\title{
ORGANIC ATMOSPHERIC POLLUTANTS: POLYCYCLIC HYDROCARBONS FROM COAL ATMOSPHERIC FLUIDISED BED COMBUSTION (AFBC)
}

\section{A. M. MASTRAL \\ M. S. CALLEN \\ R. MURILLO \\ T. GARCIA}

Received: 23/6/98

Accepted: 20/6/99
Instituto de Carboquimica,

CSIC, PO Box 589, 50080-Zaragoza, Spain

\section{ABSTRACT}

The work deals with coal combustion in a pilot-plant fluidised bed $(7 \mathrm{~cm}$ i.d.) under atmospheric conditions. The aims are to capture and analyse qualitatively as well as quantitatively the volatile polycyclic hydrocarbons emitted by using coal as energy source under various combustion conditions. After establishing the sampling procedure, the emissions are caught in five different traps (two cyclones, nylon and teflon filters, and XAD-2). The contribution of each of the sixteen polycyclic aromatic hydrocarbons (PAH) listed by the US Environmental Protection Agency (EPA) as priority pollutants is analysed, and their emissions as a function of the combustion variables (combustion temperature, percentage of excess oxygen, air flow and fluidising agent) are reported. Synchronous Fluorescence Spectroscopy is the analytical tool used for identification and quantification of the PAH emissions.

KEYWORDS: atmospheric contamination, coal combustion, fluidised bed, organic emissions, polycyclic hydrocarbons, analysis

\section{INTRODUCTION}

Nowadays in most countries, coal constitutes the main source in power stations to produce electrical energy. For many years, the only limitation for these stations has been the control of $\mathrm{NO}_{\mathrm{X}}, \mathrm{SO}_{\mathrm{X}}, \mathrm{CO}_{\mathrm{X}}$ and particulate matter emissions (Nordin, 1995).

Fluidised bed reactors are the last generation reactors for coal combustion. From these, atmospheric fluidised bed combustion (AFBC) is generally considered to be an environmentally favourable combustion technology, where control of emissions can be integrated into the combustion system. AFBC systems burning coal usually operate with a combustion zone temperature of around $800-900^{\circ} \mathrm{C}$, more specifically at $860^{\circ} \mathrm{C}$. These low temperatures not only prevent thermal NO formation but promote NO-reducing reactions during the combustion process. The temperature range in AFBC is also suitable for addition of sorbent into the bed for sulphur removal by 
reducing $\mathrm{SO}_{2}$ emissions. At $860{ }^{\circ} \mathrm{C}$, limestone reaches the maximum efficiency capturing sulphur with the minimum limestone addition. In any case, optimal process conditions have to be identified whenever opposing effects are observed. For instance, there is a strong effect of temperature on sorbent demand if the combustion temperature in the FBC is outside the optimal range.

On the other hand, $\mathrm{NO}$ emissions increase as temperature increases, whereas $\mathrm{N}_{2} \mathrm{O}$ emissions show exactly the opposite trend. Due to the range of temperatures used in FBC, the emissions of $\mathrm{CO}$ are, in general, higher than in conventional boilers. Another important factor is the excess oxygen, which mainly affects the emissions of $\mathrm{NO}_{\mathrm{X}}$ and $\mathrm{CO}$, together with the economical aspect of the process. The $\mathrm{NO}_{\mathrm{X}}$ decrease with decreasing amount of excess air. A decrease in excess oxygen will, however, increase the $\mathrm{CO}$ emission and result in decreased combustion efficiency. Both operating factors, bed temperature and excess oxygen, as well as primary air/fuel ratio or sorbent feed rate, have been extensively studied and reported (Hjalmarsson, 1992), but only for the above cited pollutants.

Current research aims toward technical and economic improvements seeking new ways to get cheaper and cleaner coal-conversion processes. The work conditions and the possible modifications carried out have been focused on the use of different mechanisms, like washing and desulphurization of coal, addition (Wasi et al., 1995) of $\mathrm{CaSO}_{4}$ to retain and to avoid high emissions of sulphur compounds, in order to abate atmospheric pollution.

In the reported work so far, it has not been taken into account the effect of other emissions to the atmosphere except for the ones mentioned above. However, there are other emissions with even higher negative environmental impact: the Volatile Organic Compounds (VOC) (Chagger et al., 1997). From these VOC, the polycyclic aromatic compounds (PAC), and within these, the polycyclic aromatic hydrocarbons (PAH) (Williams, 1990; Lee, 1981; Tongwell, 1983; and Barfnedit et al., 1980), constitute some of the most dangerous compounds, due to their possibility of interacting with biological nucleophiles, such as proteins, inhibiting the regular metabolic functions of the cells and causing carcinogenesis.
Nowadays, there is a growing interest in $\mathrm{PAH}$ emissions in the concern about the VOC emissions (Williams et al., 1995; Zhang et al., 1996; and Mastral et al., 1997), because it is expected that new legislation regulating the emissions of these compounds will be very restrictive. Concerning the PAH emissions, their origin can be double (Mastral et al., 1997): (i) the aromatic coal structure and/or (ii) the pyrolytic process associated with any combustion process. One way to abate their emissions could be the control of the different variables that affect combustion (Mastral et al., 1997).

Therefore, it would be necessary to study the $\mathrm{PAH}$ formation in relation to combustion process conditions (Bonfanti et al., 1994), with the aim of minimising their formation. Some of the variables, such as the nature of coal (Akers et al., 1994), are difficult to modify while others, such as combustion temperature (Mastral et al., 1996) and percentages of excess oxygen (Mastral et al., 1998), should be controlled to avoid higher emissions.

In this paper, the coal AFBC is carried out in a pilot plant, where the combustion efficiency reached is higher than $99 \%$, and so one of the two possible causes of $\mathrm{PAH}$ emissions has been minimised. A wide range of combustion temperatures, different percentages of excess oxygen and different air flows have been tested. The corresponding PAH emissions, once analysed, are studied as a function of the combustion variables.

\section{EXPERIMENTAL}

A low rank coal from N-E of Spain (SAMCA) has been burned (0.5-1 mm particle size) in a fluidised bed reactor (14) with sand as fluidising agent. The coal ultimate and proximate analysis are: $\mathrm{C}(\%$ daf): $73.8 ; \mathrm{N}(\%$ daf): $0.9 ; \mathrm{S}(\% \mathrm{db}): 6.3$; $\mathrm{H}$ (\% daf): 6.4 ; ash (\% ar): 23.9 ; volatiles ( $\%$ ar): 15.0; and moisture (\% ar): 15.7 .

The combustion experiments were performed at different temperatures $\left(650^{\circ} \mathrm{C}, 700^{\circ} \mathrm{C}, 750^{\circ} \mathrm{C}\right.$, $800^{\circ} \mathrm{C}, 850^{\circ} \mathrm{C}, 900^{\circ} \mathrm{C}$ and $\left.950^{\circ} \mathrm{C}\right)$, different percentages of excess oxygen $(5 \%, 10 \%, 20 \%$ and $40 \%)$ and at different flows $(700 \mathrm{l} / \mathrm{h}, 800 \mathrm{l} / \mathrm{h}, 860$ $\mathrm{l} / \mathrm{h}, 900 \mathrm{l} / \mathrm{h}, 1000 \mathrm{l} / \mathrm{h}$ and $1100 \mathrm{l} / \mathrm{h}$ ). In addition, sand and limestone were used at fluidising agents. In all cases, the sampling time was two hours, when the combustion was in optimal operation conditions, with the aim of avoiding starting 
times, which increase PAH emissions.

From each experiment five samples from the two cyclones (first and second cyclone), bubbling system, nylon filter $(20 \mu \mathrm{m})$ and XAD-2 resin, were extracted (Mastral et al., 1995a) by ultasonic bath per 15 minutes. The airflow was forced to pass through the bubbling system, composed of a DMF solution, with the objective to retain possible PAH and to condense the water generated during the process. The samples were analysed by fluorescence spectroscopy in synchronous mode (FS) following the analytical conditions reported in our previous work (Mastral et al., 1995b).

\section{RESULTS AND DISCUSSION}

Although coal aromaticity is not as high as it was believed few years ago (Mochida, 1995), the newest analytical techniques applied to coal study have shown that the deduction of coal aromaticity through its conversion products gives higher values than the real ones. The dominant component of coal seems to be composed by a threedimensional network of condensed aromatic and hydroaromatic units connected by weaker bonds. During coal combustion, some of these units can be emitted as unburned material and this would be one of the causes of organic emissions. To avoid this kind of emissions, the combustion efficiency should be as close as possible to $100 \%$. For the low-rank coal studied and at the laboratory scale plant used in this work (Mastral et al., 1997), the efficiencies reached as a function of combustion temperatures and as a function of the percentages of excess oxygen are shown in Tables 1 and 2 , respectively.

The second cause of organic emissions can be the pyrolytic process associated with any combustion process. When coal undergoes pyrolysis, important physical and chemical changes (Mastral et al., 1998a) occur, and radicals are released, which, generally speaking, stabilise between themselves by cyclation reactions. In addition, and as consequence of the thermal process, further aromatic clusters can be developed. Both, the inherent aromatics and those generated during the thermal process, are significant atmospheric pollutants, mostly those composed by carbon and hydrogen (PAH), because once in the human body, by ingestion and/or by breathing, modify the regular metabolism of the biological nucleophylics.

In order to assess the PAH emissions as a function of the combustion variables, the first aim of this study was to reach the maximum combustion efficiency. Once it was reached, see Tables 1 and 2 , it can be assumed that the emissions due to a bad combustion have practically been eliminated, and so the data obtained will be due to the combustion process and not a consequence of the material being burnt.

The influence of the combustion temperature was studied between $650^{\circ} \mathrm{C}$ and $950^{\circ} \mathrm{C}$. The amounts of each PAH studied, captured under various temperatures in each trap, are shown in Table 3 and the total emissions are shown in Figure 1. As the combustion efficiency is constant and very close to $100 \%$, these data provide information about the importance of the pyrolytic process and show that the radicals interactions depend on the specific temperature at the top of the reactor, when the percentage of excess oxygen and the air flow are kept constant. The maximum emissions of total $\mathrm{PAH}$ are between $750^{\circ} \mathrm{C}$ and $850^{\circ} \mathrm{C}$, which are the temperatures currently used at the new power stations.

Concerning the distribution of the total PAH

Table 1. Combustion efficiencies reached as a function of the combustion temperatures

(SAMCA coal, FBC, 20\% excess oxygen, 860 1/h)

\begin{tabular}{llllllll}
$\mathbf{T}(\mathbf{0} \mathbf{C})$ & $\mathbf{6 5 0}$ & $\mathbf{7 0 0}$ & $\mathbf{7 5 0}$ & $\mathbf{8 0 0}$ & $\mathbf{8 5 0}$ & $\mathbf{9 0 0}$ & $\mathbf{9 5 0}$ \\
\hline Efficiency & 99.1 & 98.8 & 99.0 & 99.0 & 99.1 & 99.3 & 99.4
\end{tabular}

Table 2. Combustion efficiencies reached as a function of the percentage of excess oxygen (SAMCA coal, $\mathrm{FBC}, 850^{\circ} \mathrm{C}, 860 \mathrm{l} / \mathrm{h}$ )

\begin{tabular}{lcccc} 
\% Excess oxygen & $\mathbf{5}$ & $\mathbf{1 0}$ & $\mathbf{2 0}$ & $\mathbf{4 0}$ \\
\hline Efficiency & 98.7 & 99.3 & 99.5 & 99.6
\end{tabular}


amount emitted, keeping constant the temperature and the air flow, and according to Table 4 and Figure 2, it can be observed that with the lowest percentage of excess oxygen, the highest PAH amount is emitted, showing a minimum emission when coal is burnt with $20 \%$ of excess oxygen. Greater excess oxygen than $20 \%$ generates more PAH emissions.

From the PAH amounts collected in each trap, it could not be possible to guess a definite trend on PAH distribution as a function of each trap. This random distribution was also observed when the other combustion variables were studied. However, at the lowest percentages of excess oxygen, most of the total amount of PAH emitted are supported on the particulate matter trapped in first cyclone. When the percentages of excess oxygen increase, in general, the first cyclone amount decreases.

One of the most interesting compounds to study is Coronene. In most of the samples, Coronene is the majority component, especially for those obtained al low percentages of excess oxygen. This fact could indicate that the aromatic radicals formed in the first stages of combustion tend to stabilise, by forming species as Coronene by pyrosynthesis, and this mechanism seems to be favoured by low velocities in the post-combustion area. In a first approach, the formation of Coronene is an advantage in terms of pollution control. Coronene stability is related to its inertness, so these results seem to indicate that the way of reducing hazardous PAH emissions could be to increase residence time of radicals, but in the presence of a bulky excess oxygen, to promote the formation of more stable PAH.

Table 3. Amount (ng/kg) collected from each studied PAH and emitted from a FBC pilot plant with the SAMCA coal at $860 \mathrm{l} / \mathrm{h}, 20 \%$ excess oxygen, and different combustion temperatures

\begin{tabular}{lccccccc} 
Temperature & $\mathbf{6 5 0}^{\circ} \mathbf{C}$ & $\mathbf{7 0 0}^{\circ} \mathbf{C}$ & $\mathbf{7 5 0}^{\circ} \mathbf{C}$ & $\mathbf{8 0 0}^{\circ} \mathbf{C}$ & $\mathbf{8 5 0}^{\circ} \mathbf{C}$ & $\mathbf{9 0 0}^{\circ} \mathbf{C}$ & $\mathbf{9 5 0}^{\circ} \mathbf{C}$ \\
\hline Fluorene & 1550,2 & 1058,6 & 3632,8 & 3041,5 & 1639,9 & 850,7 & 1672,2 \\
BaP & 39,4 & 73,2 & 116,3 & 111,4 & 690,7 & 135,1 & 47,9 \\
Pyrene & 58,5 & 29,9 & 402,9 & 276,1 & 157,6 & 123,0 & 114,4 \\
Chrysene & 472,4 & 396,5 & 1186,0 & 826,1 & 917,6 & 321,9 & 127,9 \\
Anthracene & 988,0 & 776,3 & 1835,0 & 2449,7 & 1065,5 & 558,7 & 859,7 \\
Acenaphthene & 1272,4 & 4513,4 & 6800,0 & 2464,9 & 2481,2 & 2693,0 & 1709,5 \\
BaA & 91,2 & 339,1 & 461,3 & 305,0 & 453,8 & 96,3 & 164,0 \\
D(a,h)A & 84,4 & 71,3 & 260,9 & 118,0 & 104,7 & 32,0 & 62,1 \\
Coronene & 1047,5 & 388,2 & 1213,7 & 3458,6 & 2850,3 & 316,4 & 901,7 \\
Perylene & 10,2 & 49,8 & 120,4 & 107,8 & 138,8 & 44,2 & 17,4 \\
BkF & 0,0 & 56,8 & 0,0 & 68,6 & 180,5 & 40,1 & 0,0 \\
\hline
\end{tabular}

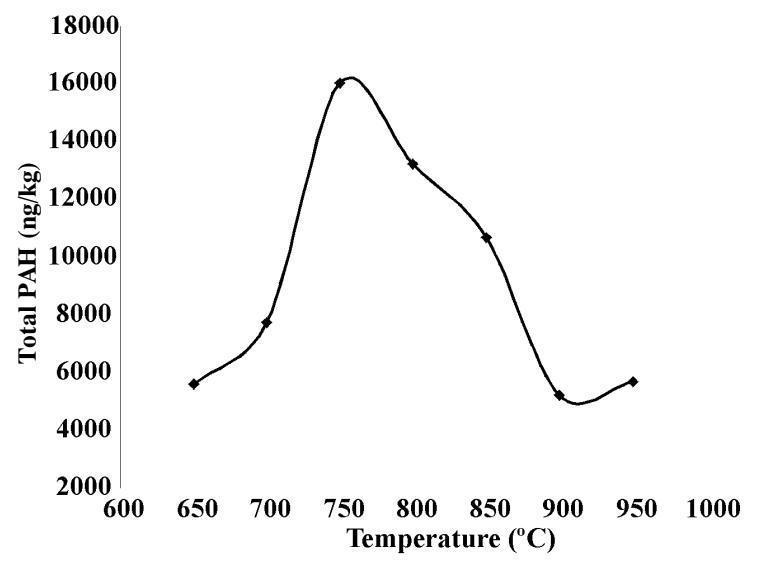

Figure 1. Total PAH emitted as a function of the combustion temperature in $\mathrm{FBC}(860 \mathrm{l} / \mathrm{h}$, $20 \%$ excess oxygen, SAMCA coal)
One of the main motivations previously mentioned to study PAH emissions is because of the carcinogenic effect of some of these compounds. Within this group, $\mathrm{BaP}$ and $\mathrm{D}(\mathrm{a}, \mathrm{h}) \mathrm{A}$ present the highest interest because they are the most carcinogenic compounds. The results obtained show low values and a minimum contribution of these two compounds to the total PAH emissions from coal combustion.

On the other hand, due to their carcinogenic effect, it should be interesting to know the PAH distribution once emitted to the atmosphere, see Figure 3. While those emitted on the particulate matter and trapped on cyclones are not released to the atmosphere, the PAH emitted in the gas phase, would be released to the atmosphere 


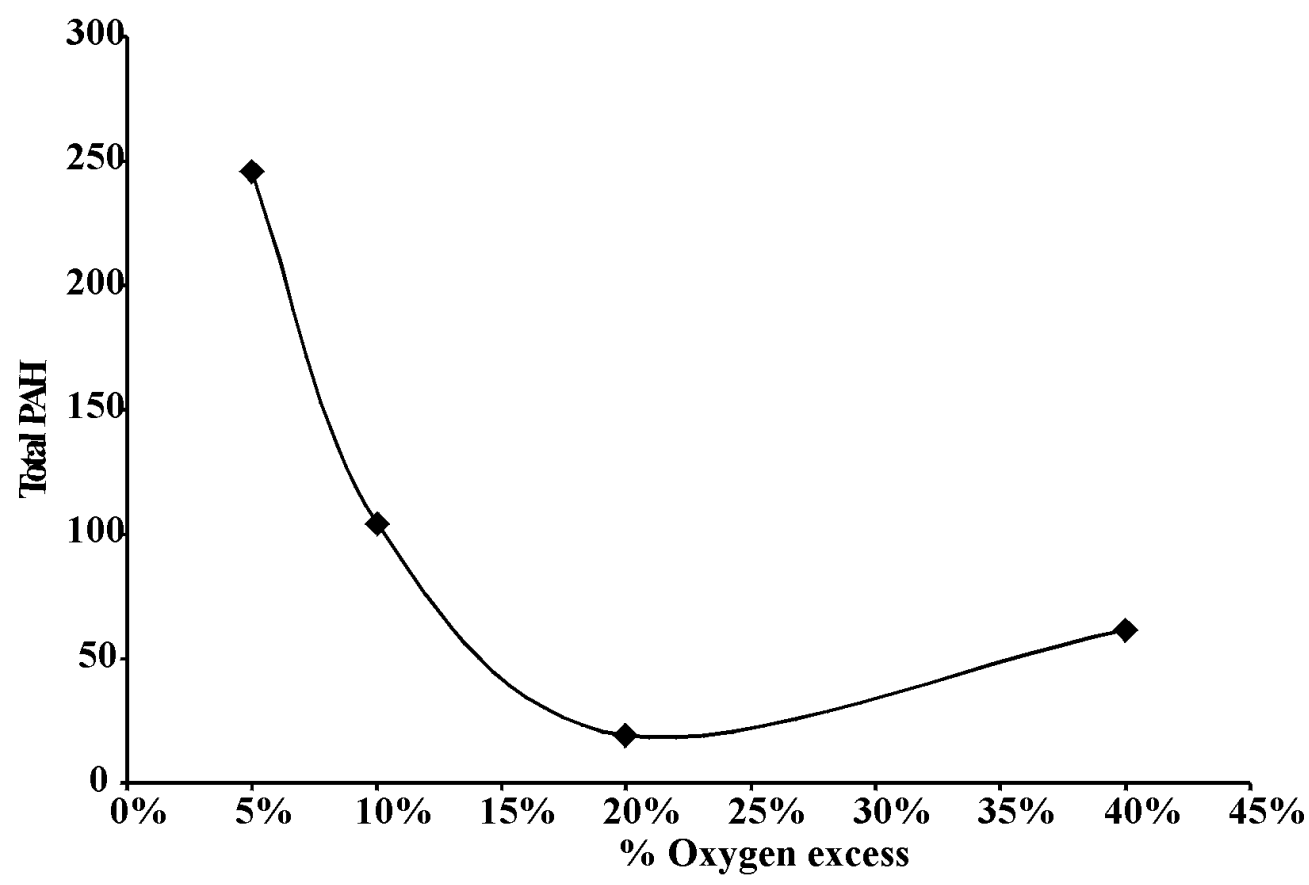

Figure 2. Variation of the total PAH $(\mu \mathrm{g} / \mathrm{kg})$ emitted as a function of the percentages of excess oxygen $\left(850^{\circ} \mathrm{C}, 860 \mathrm{l} / \mathrm{h}\right.$, SAMCA coal $)$

affecting large areas. These last compounds could be transported over long distances undergoing photochemical reactions, which would turn them into even more hazardous pollutants. So, the distribution between solid and gas phases has been studied, assuming that those PAH in solid state or supported on the particulate matter were trapped by the first and second cyclone, and those collected in the bubbling system, nylon filter and adsorbent were included in the gas phase. Moreover, the ones trapped on cyclones, in commercial plants are recycled to the bed in order to improve combustion efficiency. In this work, the results on PAH distribution in the solid/gas phase are shown in Figure 3.

From Figure 3 it is deduced that the highest the percentage of excess oxygen, the highest the PAH amount formed in gas phase. It is to say, the lowest percentages of excess oxygen could favour the highest PAH deposition on particulate mat-

Table 4. PAH $(\mu \mathrm{g} / \mathrm{kg})$ trapped in coal $\mathrm{FBC}$ al $850^{\circ} \mathrm{C}, 860 \mathrm{l} / \mathrm{h}$ and different percentages of excess oxygen

\begin{tabular}{lcccc} 
Excess oxygen & $5 \%$ & $10 \%$ & $20 \%$ & $40 \%$ \\
\hline Fluorene & 43,16 & 20,87 & 11,78 & 2,52 \\
BaP & 3,37 & 0,52 & 0,03 & 1,30 \\
Pyrene & 23,21 & 4,71 & 1,34 & 9,66 \\
Chrysene & 38,10 & 8,24 & 0,00 & 0,65 \\
Anthracene & 1,85 & 0,72 & 0,00 & 0,12 \\
Acenaphthene & 36,12 & 14,73 & 0,00 & 25,55 \\
BaA & 16,21 & 6,69 & 0,00 & 2,73 \\
D(a,h)A & 1,54 & 2,63 & 0,00 & 0,02 \\
Coronene & 81,84 & 45,21 & 5,06 & 19,25 \\
Perylene & 0,46 & 0,11 & 0,91 & 0,00 \\
BkF & 0,00 & 0,00 & 0,00 & 0,00 \\
\hline
\end{tabular}




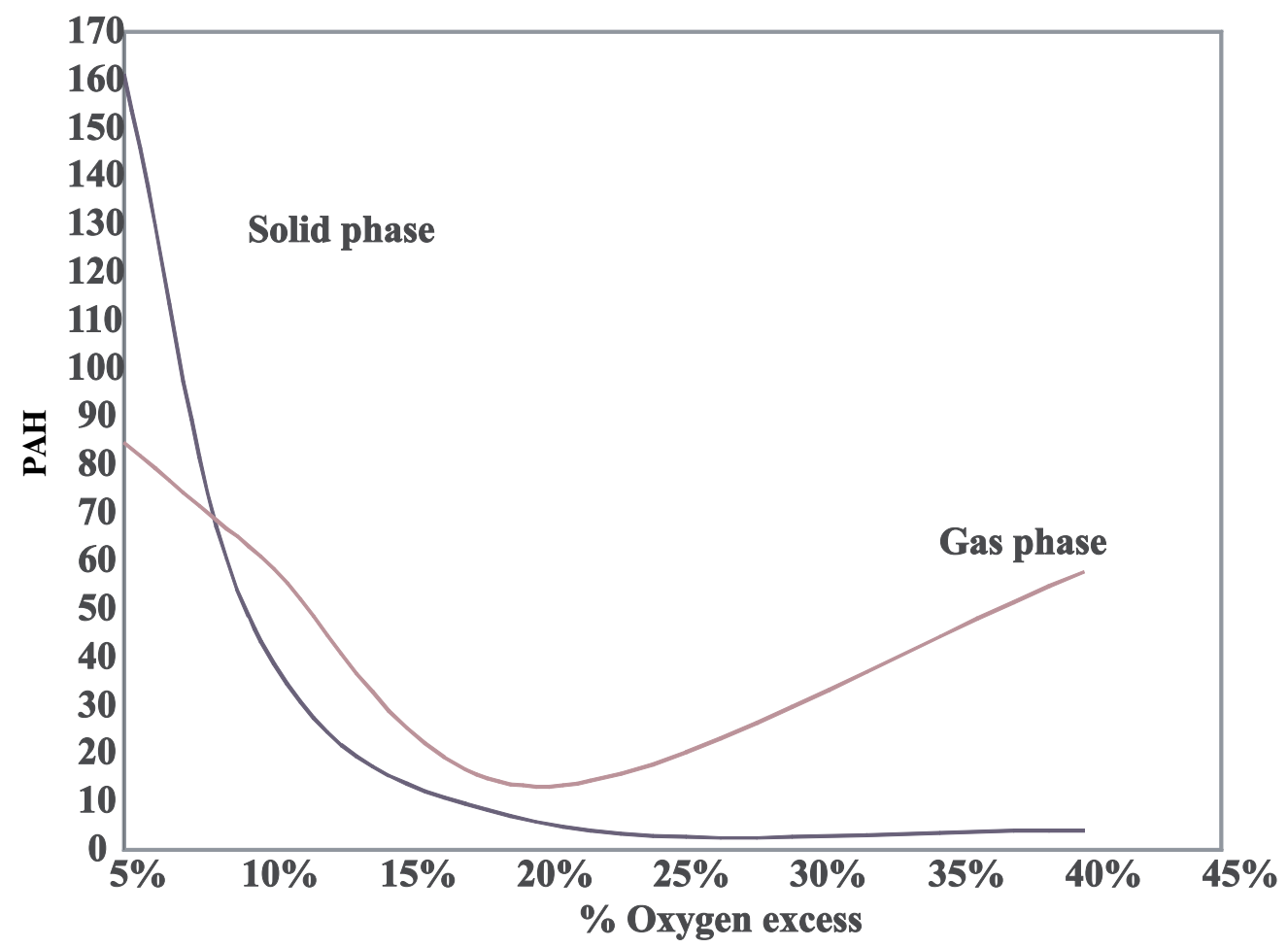

Figure 3. PAH $(\mu \mathrm{g} / \mathrm{kg})$ distribution between solid and gas phases as a function of the percentages of excess oxygen in coal $\mathrm{FBC}\left(850^{\circ} \mathrm{C}, 860 \mathrm{l} / \mathrm{h}\right.$, SAMCA coal)

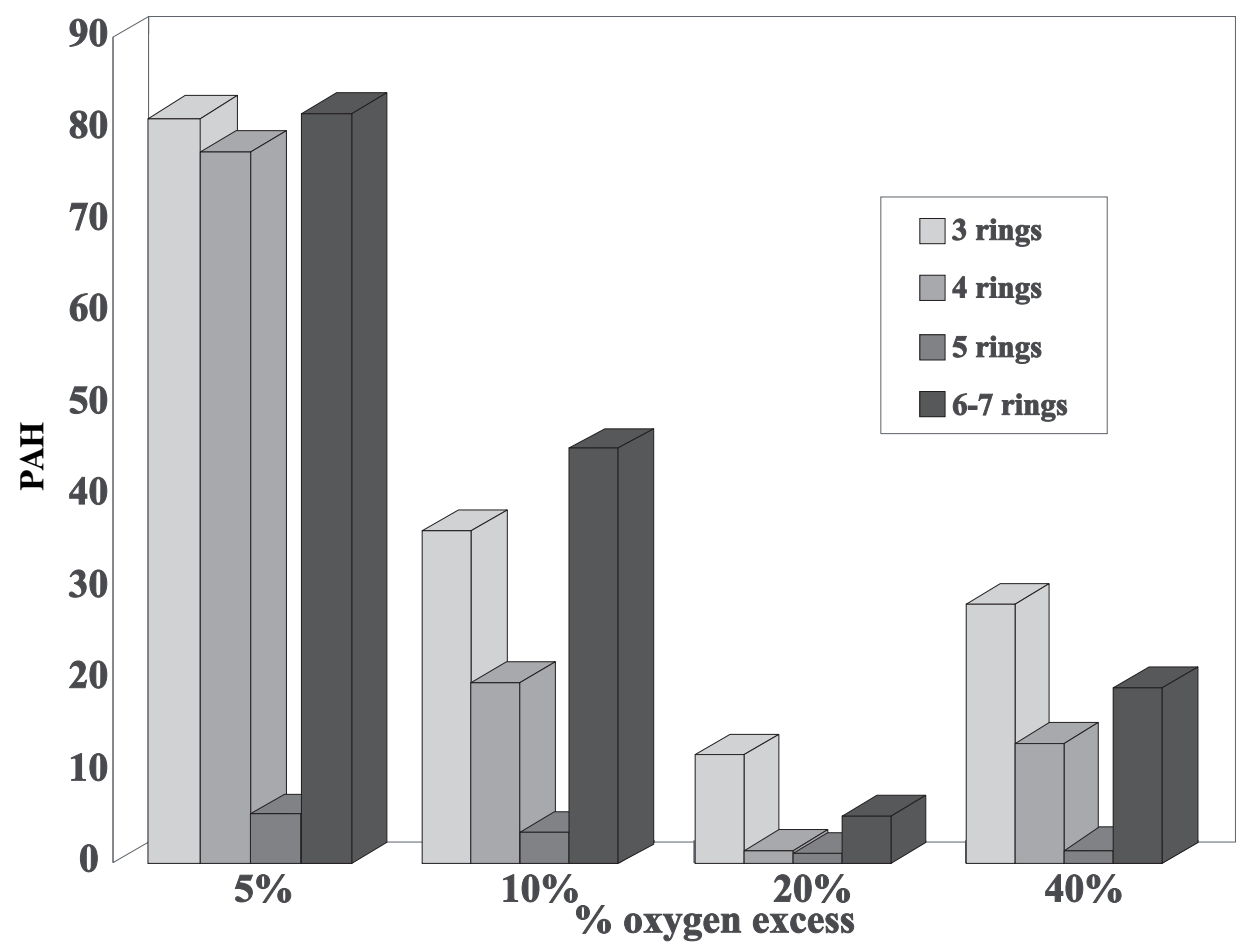

Figure 4. PAH $(\mu \mathrm{g} / \mathrm{kg})$ distribution by number of rings as a function of the percentage of excess oxygen from coal combustion in a $\mathrm{FBC}$ at $850^{\circ} \mathrm{C}, 860 \mathrm{l} / \mathrm{h}$, SAMCA coal 
ter, while the highest percentages of excess oxygen could favour the swept of PAH to the gas phase.

Under real working conditions of a power plant, according to this data distribution, it could be deduced that at the lowest percentages of excess oxygen, the PAH would affect mostly the surroundings of the power plant, by deposition of the particulate matter. At the highest percentages of excess oxygen, the contamination would affect non-specific and larger areas.

Due to the relevance of the percentage of excess oxygen on PAH emissions, the distribution of PAH by rings number has been also studied, see Figure 4.

Figure 4 shows that, in all cases, independently of the excess oxygen, the PAH with 3 and 6-7 rings in their molecules are the most abundant. PAH with 5 rings are always the least and their relative variation with the excess oxygen is minimum.

The highest percentages of excess oxygen seem to minimise possible interactions between $\mathrm{PAH}$, making difficult their inter-conversion, association and other condensation reactions, and giving as a result the lowest hydrocarbons emissions (Mastral et al., 1998b). Perhaps it is due to the formation of substituted PAH, PAC and other oxygenated compounds, a consequence of the interaction between oxygen atoms and radicals. In this way, at the lowest percentages of excess oxygen, this interaction between oxygen and radicals should be less favoured, and as a result, the PAH amount emitted would be higher.

The influence of the airflow rate on $\mathrm{PAH}$ emissions has been studied keeping constant the combustion temperature and the percentage of excess oxygen. Each component of the PAH emitted, varying the airflow rate from 700 to $1100 \mathrm{l} / \mathrm{h}$, is shown in Table 5, and the total PAH emitted in this range is shown in Figure 5.

Generally, the higher the flow rate, the higher the hydrocarbon emissions, but a dramatic increase on total PAH emission is observed between $860 \mathrm{l} / \mathrm{h}$ and $900 \mathrm{l} / \mathrm{h}$ (Fig. 5). It is assumed that this huge increase is due to the fluidised bed characteristics. An increase in the airflow rate from $700 \mathrm{l} / \mathrm{h}$ to $860 \mathrm{l} / \mathrm{h}$ means a better mixture of the bed solids with the air bubbles, which allows a better fluidisation and oxidation of the released coal radicals, and so a reduction on $\mathrm{PAH}$ emission by radicals elimination. But the fluidised beds show some problems when the gas velocity is too high with respect to the minimum fluidising velocity. At higher gas velocities, slugging or choking regimens seem to occur in small-diameter vessels, shortening the gas-solids contact. At these conditions, most of the oxygen at the air bubbles is lost without interacting with radicals, so without producing radical oxidation increasing the corresponding $\mathrm{PAH}$ emission, as it is observed in Fig. 5. It seems that at $880 \mathrm{l} / \mathrm{h}$, the inflection point on the curve corresponds to a slugging regime, while at higher flow rates $(900$ 1/h) a choking regime seems to take place.

Other variables studied were the fluidising agent, sand and limestone at different percentages of excess oxygen maintaining as constant the rest of the variables: combustion temperature and total airflow rate. Most of the combustion

Table 5. Individual PAH $(\mu \mathrm{g} / \mathrm{kg})$ emitted from coal $\mathrm{FBC}$ as a function of airflow rate $\left(850^{\circ} \mathrm{C}, 10 \%\right.$ excess oxygen, SAMCA coal)

\begin{tabular}{lcccccc} 
Flow rate $(\mathbf{l} / \mathbf{h})$ & $\mathbf{7 0 0}$ & $\mathbf{8 0 0}$ & $\mathbf{8 6 0}$ & $\mathbf{9 0 0}$ & $\mathbf{1 0 0 0}$ & $\mathbf{1 1 0 0}$ \\
\hline Fluorene & 316,2 & 83,3 & 20,9 & 256,2 & 504,3 & 414,0 \\
BaP & 10,3 & 4,4 & 0,5 & 35,4 & 26,0 & 29,2 \\
Pyrene & 123,5 & 99,2 & 4,7 & 530,8 & 322,8 & 328,3 \\
Chrysene & 104,8 & 41,8 & 8,2 & 825,0 & 299,0 & 901,5 \\
Anthracene & 0 & 2,9 & 0,7 & 34,5 & 0 & 42,6 \\
Acenaphthene & 421,1 & 117,0 & 14,7 & 959,4 & 1034,1 & 598,6 \\
BaA & 32,6 & 6,5 & 6,7 & 60,1 & 26,1 & 44,6 \\
D(a,h)A & 5,6 & 2,1 & 2,6 & 0 & 5,1 & 5,7 \\
Coronene & 69,3 & 33,0 & 45,2 & 0 & 72,0 & 0 \\
Perylene & 0 & 0 & 0,1 & 0 & 0 & 0 \\
BkF & 0 & 0 & 0 & 0 & 0 & 0 \\
\hline
\end{tabular}






Figure 5. Total PAH $(\mu \mathrm{g} / \mathrm{kg})$ distribution emitted from coal $\mathrm{FBC}$ as a function of airflow rate $\left(850^{\circ} \mathrm{C}, 10 \%\right.$ excess oxygen, SAMCA coal)

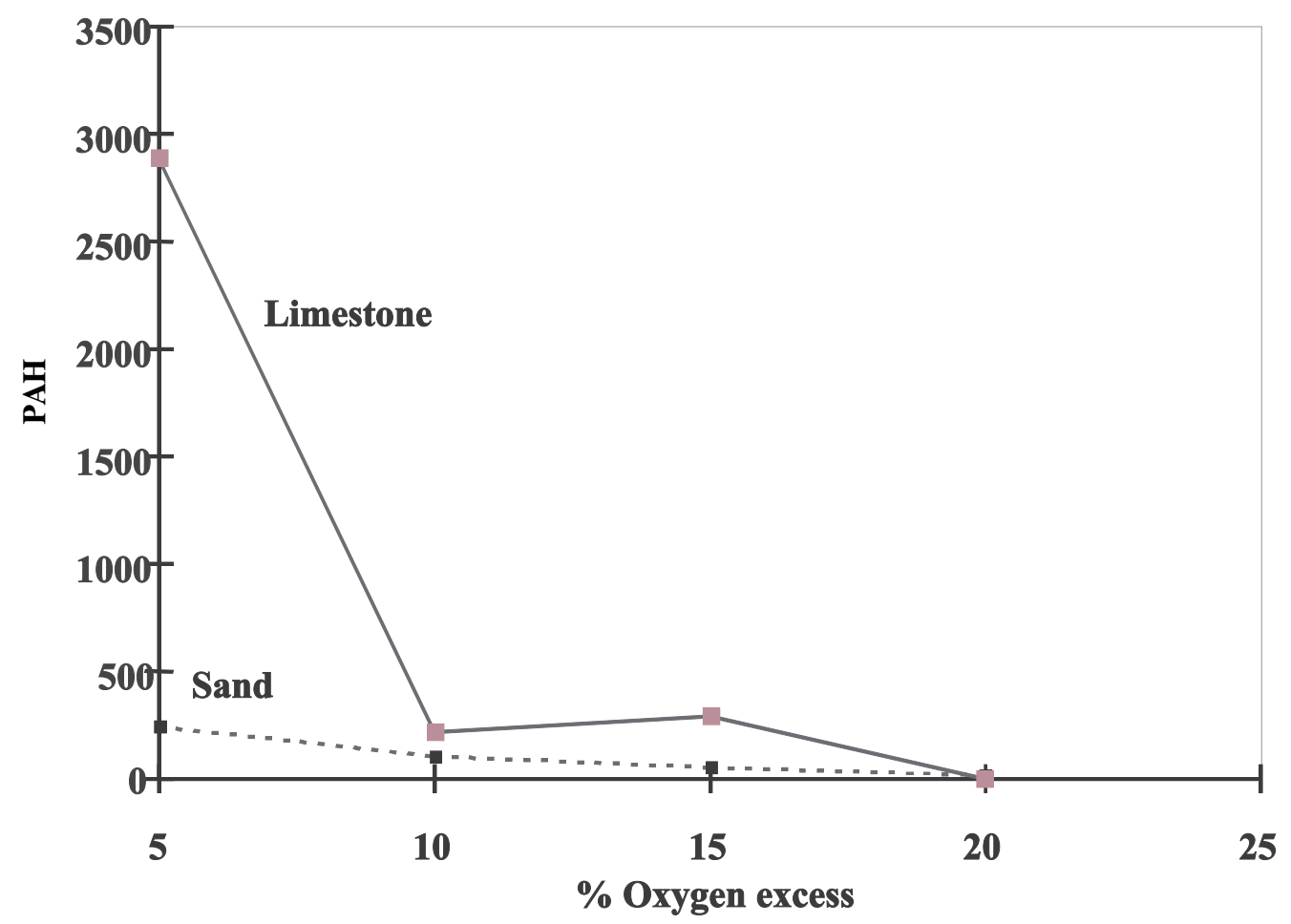

Figure 6. Total PAH $(\mu \mathrm{g} / \mathrm{kg})$ emitted at different percentages of excess oxygen with sand and limestone as fluidising agents $\left(850^{\circ} \mathrm{C}, 860 \mathrm{l} / \mathrm{h}\right.$, SAMCA coal $)$ 
processes were carried out with sand as inert material, in order to avoid the influence of strange artefacts in the PAH formation and emissions. But at the power stations, limestone is used to abate sulphur emissions. Therefore, some combustions were performed with limestone, varying the percentage of excess oxygen. Figure 6 shows the PAH emissions with the two agents: sand and limestone at the same conditions, $850^{\circ} \mathrm{C}, 860 \mathrm{l} / \mathrm{h}$ and different percentages of excess oxygen.

It can be seen that with high percentages of excess oxygen, the emissions are quite similar. However, at percentages of excess oxygen near the values used at the power stations, i.e. lower than $10 \%$, the PAH emissions with limestone are higher than those with sand. The reason is not yet known but the limestone pore distribution could play an important role as well (Mastral el al., 1998c).

Summarising, it could be concluded that for the conditions used at the new power stations, using fluidised bed reactors with limestone for $\mathrm{SO}_{\mathrm{X}}$ and $\mathrm{NO}_{\mathrm{X}}$ abatement, and operating at $850^{\circ} \mathrm{C}$ and $860 \mathrm{l} / \mathrm{h}$, a $10 \%$ excess oxygen is the minimum that should be used in order to reduce the PAH emissions.

\section{ACKNOWLEDGEMENTS}

The authors would like to thank the partial financial support of this work by the European Union and by the Spanish CICYT (COMISION INTERNATIONAL DE CIENCIA Y TECNOLOGIA).

\section{REFERENCES}

Akers, D.J. and Dospoy, R.L. (1994), Fuel Processing Technology, 39.

Anders Nordin, (1995), Fuel, 74, 615-622.

Barfnedit, T.R., Andon, B.M., Thilly, W.G. and Hithes, R.A. (1980), Soot and mutation in bacteria and human cells, in M. Cooke and A.J. Dennis (Eds), Chemical Analysis and Biological Fate: Polycyclic Aromatic Hydrocarbons, Battelle Press, Columbus, Ohio.

Bonfanti, L., de Michele, G., Riccardi, J. and Lopez-Doriga, E. (1994), Combust. Sci. Tech., 101, 505-525.

Chagger, H.K., Jones, J.M., Pourkashanian, M. and Williams, A. (1997), Fuel, 76, 861-864.

Hjalmarsson, K.A. (1992), Interactions in emissions control for coal-fired plants, IEACR/47, IEA Coal Research, London.

Lee, M., Novotny, M. and Bartle, K.D. (1981), Analytical Chemistry of Polycyclic Aromatic Compounds, Academic Press, New York.

Longwell, J.P. (1983), Soot in Combustion Systems and its Toxic Properties, in J. Lahaye and G. Prado (Eds), Plenum Press, New York.

Mastral, A.M., Callen, M.S., Mayoral, M.C, Galban, J. (1995a), Fuel, 74, 1762-1766

Mastral, A.M., Galban, J., Pardos, C., Rubio, B. (1995b), Microanalyitical Letters, 28, 1883-1895

Mastral, A.M., Callen, M.S., Murillo, R. (1996), Fuel, 75, 1533-1536

Mastral, A.M. (1997), Formation of PAH during coal processing, Final Report ICSC to The EU, Contract Ref 7220/EC/026.

Mastral, A.M., Perez, M.L. and Palacios, J.M. (1998a), Fuel, 77, 585-590

Mastral, A.M., Callen, M.S., Murillo, R., Garcia, T. (1998b), Fuel, 77, 1513-1516.

Mastral, A.M., Garcia, T., Callen, M.S., Murillo, R., Mayoral, C. and Tejero, M.P. (1998c), V International Symposium on Analytical Methodology in the Environmental Field, La Coruna, April, II, 1-2.

Mochida, L. (1995), Plenary Lecture on Coal Study throughout History, al the 1995 ICCS, Oviedo, Spain.

Wasi, Z. Gibbs Khan and Bernard M. (1995), Fuel, 74, 800-805

Williams, P.T. (1990), Sampling and analyses of polycyclic aromatic compounds from combustion systems- a review. J. Inst. Energy, 63, 22-30.

Williams, P.T., Nazzal, J.M. (1995), Polycyclic aromatic compounds in oils derived from the fluidised bed pyrolysis of oil shale. J. Anal. Appl. Pyrolysis, 35, 181-197. 